\title{
The design and construction of a chamber with controlled temperature and humidity $^{*}$
}

\author{
by Professor J. W. H. King, M.Sc., M.I.C.E., M.I.Struct.E. and J. Timusk, M.A.Sc.
}

\section{Contribution by C. K. Andrews, M.Sc.(Tech.), A.M.I.Mech.E. Charles Andrews \& Sons, Consulting Engineers}

The paper is of particular interest to me since I have been considering a similar design, using a salt bath for humidity control of part of a laboratory. In this case, since the laboratory is only part of a consulting engineer's practice, the use is intermittent, and it is therefore difficult to justify the expense of conventional equipment.

The operating experience reported in the paper will encourage us to think in terms of an enclosure larger than that originally planned, but it may be of interest to mention some design features which were thought advisable for a room of approximately half the volume of that designed by Professor King and Mr Timusk.

We were fortunate in having an inner room in a cellar, without windows, which made temperature control comparatively easy. In such a small enclosure, it was considered that the presence of one or two people and the disturbance on entering and leaving could affect the humidity directly, and therefore the design incorporates a humidistat, in addition to thermostats, arranged to operate a fan drawing air from the laboratory or from the adjacent cellar, and blowing into the laboratory over a separate salt bath to give a temporary supply of air of a relative humidity lower than the controlled value.

Since it is not likely that there will be any disturbance tending to reduce the humidity, the humidistat would be set to operate on a rise in relative humidity and provide the supply of drier air to compensate for any time lag in the main control system.

Initially it is proposed to have one value only of controlled relative humidity, but should a wide range be needed eventually, a series of salt baths will be used, each corresponding to a different value, the humidistat then being connected to the one giving a lower humidity than the main control bath. Simple ducting arrangements will enable two fans to suffice for the duty.

The other design feature is to circulate the salt solution from the lower to upper baths continuously

*Pages 101 and 102 of Magazine No. 51. and achieve adequate contact between air and salt solution by wetted baffles.

\section{Reply by the authors}

We are glad to see that the article has aroused interest in other people wishing to provide a constant environment in a small chamber. The precautions which the contributor has suggested might possibly be necessary for a very small chamber entered by several people at the same time but are quite unnecessary in our case. It should be realized that, even if the humidity of the room changes by a small amount whilst a person is present, this is rapidly counteracted the next time the heater switches on. In any case, the effect of slight variations in humidity on the concrete specimens is far from immediate so that even considerable perturbations in the degree of humidity would be unlikely to have any effect on them.

We have usually found that the simplest possible method of tackling a job is likely to be more reliable than a more elaborate one since there are fewer things to go wrong, and suggest that some of the safeguards proposed will probably be found quite unnecessary. Whilst there is no doubt that the circulation of a salt solution would deal with the problem of salt deposition in the top trays and water deposition in the bottom trays, the need to back-transfer arises at such wide intervals that it appears to be quite unnecessary to provide continuous flow to overcome it. The narrow space between the trays and the comparatively wide tray area give, we find, all the contact between air and solution that is necessary and we put forward our design as one which has proved quite adequate over a number of years without any further elaboration. We can, in fact, envisage problems resulting from continuous circulation of salt solution over baffles as we would expect these to become clogged up by salt crystals in some regions and liable to produce migration of salt outside the humidity apparatus after some time in use.

It would be very interesting to hear from $\mathrm{Mr}$ Andrews some report on the general running of his design when it has been some time in use. 